\title{
REVERBERAÇÕES DRAMATÚRGICAS: técnica Klauss Vianna - princípios mediadores do processo criativo
}

\section{DRAMATURGICAL REVERBERATIONS: \\ Klauss Vianna's technique - mediator principles of the creative process}

REVERBERACIONES DRAMATÚRGICAS: técnica Klauss Vianna - principios mediadores del proceso creativo

\section{Valquiria Moura Vieira}

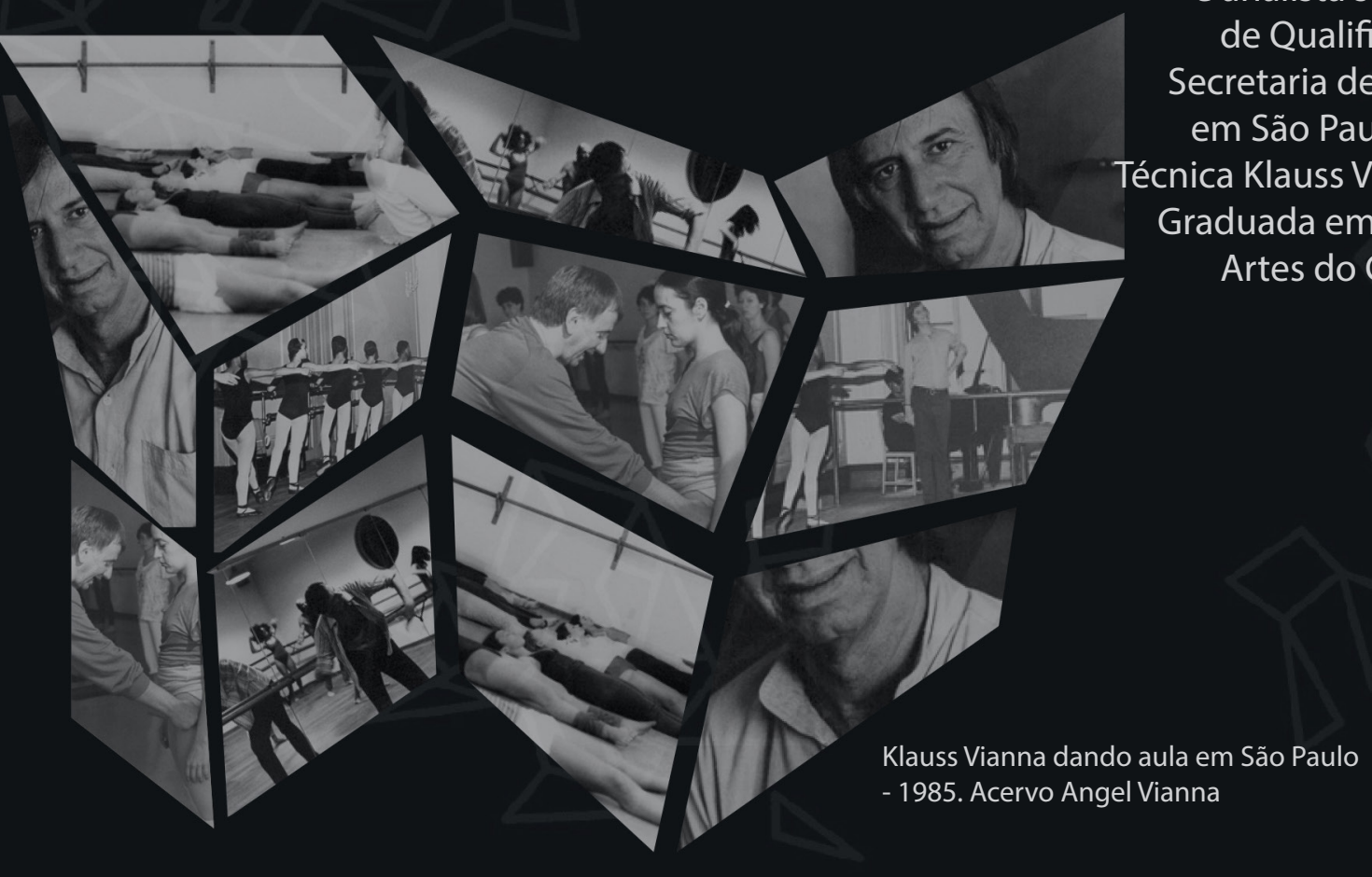

Valquiria Moura Vieira Artista de dança e teatro, fundadora da Cia. Corpocena e analista sênior do Programa alificação em Artes da a de Estado da Cultura Klauss Vianna pela PUC-SP. Comunicação das Corpo pela PUC-SP 


\section{Resumo}

Este texto propõe que a dramaturgia se constrói das relações entre ler e perguntar em um processo mediado pelos princípios que sustentam uma técnica, levando em consideração a não separação de um pensamento de corpo/mundo. A partir da técnica Klauss Vianna e da Teoria Corpomídia, articula como metodologia o diálogo entre a tríade: criação de procedimentos, estado de presença e pergunta.

Palavras-chave: Técnica Klauss Vianna, Dramaturgia, Processo criativo.

\section{Abstract}

This paper propose that dramaturgy is brought by relations between reading and asking in a process mediated by the principles that underpin a technique, taking into account its non-separation from the idea of body/world. Based on Klauss Vianna's technique and on the Theory Corpomídia, it has as methodology the dialogue between the triad: creating procedures, presence status, and question.

Keywords: Klauss Vianna's technique, Dramaturgy, Creative process.

\section{Resumen}

En este texto se propone discutir que la dramaturgia se forma por las relaciones entre leer y preguntar en un proceso mediado por los principios sostenidos por una técnica, teniendo en cuenta su falta de separación de un pensamiento de cuerpo/mundo. Desde la Técnica Klauss Vianna y la Teoría Corpomídia, se articula metodológicamente el diálogo entre la tríada: creación de procedimientos, presencia y pregunta.

Palabras clave: Técnica Klauss Vianna, Dramaturgia, Proceso de creación.

A arte como linguagem requer investigação na busca de estratégias de comunicação, o que pede a construção de metodologias de criação. Diferentemente do olhar do senso comum para a dramaturgia como a organização final da obra, opto por discutir neste artigo o processo de construção dramatúrgica e sua ligação com um modo de olhar para o corpo e, portanto, para o mundo, sendo a partir dessa visão que as escolhas dramatúrgicas acontecem. 


\section{Valquiria Moura Vieira}

O assunto dramaturgia costuma causar polêmicas. Talvez devêssemos tratá-lo no plural: dramaturgias. Um olhar plural possivelmente tiraria a disputa de razão das infrutíferas discussões, abrindo para as possibilidades inventivas. Existem diversos tipos de organização dramatúrgica, e - arriscaria dizer ainda - são infinitas as possibilidades de regras de organização que podemos criar, uma vez que, em processos de criação autorais, as regras são, normalmente, criadas pelo artista junto com a obra.

São muitas relações até chegarmos ao roteiro final de um espetáculo: a dramaturgia do movimento estabelece relações com as demais camadas dramatúrgicas da cena (corpomenteambiente). O corpo está em relação com todos os demais textos dramatúrgicos que podem compor a cena: o figurino que toca a pele, a iluminação, o chão, o cenário, objetos cênicos e, principalmente, o fato de o artista ter diante de si uma plateia. O ambiente da cena, mesmo quando construído para ser ficcional, oferece complexidade. É claro que o grau de ambivalência varia de acordo com as escolhas que envolvem essa construção, porém o corpo, que não para de se reorganizar, gera novas conexões a todo o momento. Essa reorganização processual do corpo mantém a obra em movimento, mesmo depois de considerada finalizada.

Sistemas tendem a permanecer. Tendem a durar no tempo e para isso têm que evoluir. Uma condição fundamental para isso é que sejam sensíveis aos seus ambientes, porque as crises que podem comprometer suas permanências vêm do ambiente e da posterior ressonância destas com crises internas aos sistemas. (VIEIRA, 2007, p. 23)

$\mathrm{Na}$ vida cotidiana, bem como na arte, me relaciono o tempo todo com diversos tipos de objetos e materiais e performo muitos textos. As coisas do mundo me tocam porque me relaciono com ele; são essas relações que dão sentido à vida e, por isso, geram as questões que podem produzir arte.

Se a dramaturgia é uma espécie de nexo de sentido que ata ou dá coerência ao fluxo incessante de informações entre o corpo e o ambiente; o modo como ela se organiza em tempo e espaço é também o modo como as imagens do corpo se constroem no trânsito entre o dentro (imagens que não se vê, imagens-pensamentos) e o fora (imagens implementadas em ações) do corpo organizando-se como processos latentes de comunicação. Neste caso, não estou me referindo especificamente à drama- 
turgia teatral, à dramaturgia da dança ou da performance. (GREINER, 2005, p. 73)

Se pensarmos no significado da palavra "dramaturgia", de origem grega, em que "drama-" significa ação e "-turgia" composição, organização ou forma, temos organização ou composição da ação ou ainda dar forma à ação. Essa organização acontece durante todo o processo de criação, de maneira dinâmica; conforme as escolhas vão se dando, novas conexões acontecem, num fluxo entre influências e conexões. É importante dizer que, ao falar de organização, não estou me referindo a ordenação e linearidade, mas a uma complexa rede de sentidos que se reorganiza no fazer quando uma nova informação aparece.

Se olharmos para o corpo a partir da técnica Klauss Vianna1, que não separa corpomenteambiente, não podemos tratar a dramaturgia da dança somente como dramaturgia do movimento, mas do corpo em relação a um contexto que também está em movimento.

A proposta desta tese é, portanto, a de que a noção de técnica esteja fundamentada na compreensão da unidade corpomente, na não separação entre prática e pensamento, no entendimento da participação da ação nos processos de percepção e cognição, na relação da compreensão forma e significado nos processos comunicacionais, e no entendimento de que as instruções de uma técnica, como qualquer informação, são processadas no corpo e nele se constituem. (NEVES, 2010, p. 69)

Neste artigo, proponho a problematização do conceito de dramaturgia como algo que diz respeito às complexas relações que podem articular-se ao longo de um processo criativo entre todos os textos de composição da cena: o corpo em relação.

1. Klauss Vianna (1928-1992) dedicou-se à pesquisa de movimentos corporais, a partir das direções dos movimentos do balé clássico e de estudos em anatomia com foco na estrutura óssea, sempre considerando as emoções humanas como geradoras de movimento, como também o seu inverso: o movimento como gerador de emoções. Propôs a transformação de padrões individuais de movimento como criação artística, criando instruções que desestabilizassem esses padrões em busca de novas possibilidades de criação em dança. Sua pesquisa foi sistematizada por seu filho Rainer Vianna (1958-1995) em parceria com a pesquisadora Neide Neves, resultando no que hoje conhecemos por técnica Klauss Vianna. 
Inevitável reconhecer os ecos de Noverre e das querelas do século XVII, lá trabalhadas como passo e pantomima, movimento e palavra, e aqui deslocadas para tudo o que está no corpo é pensamento, esteja na forma de movimento ou na forma de palavra. Como hoje a dança pode abrigar tanto uma quanto a outra, a tarefa passa a ser a de buscar não mais uma, mas as variadas maneiras que diferentes pensamentos de dança empregam para serem abrigados em obras de dança. (KATZ, 2010, p. 167)

Em um processo de criação autoral, lidamos com a articulação de diversos interesses, sobretudo quando essa autoria é compartilhada com outros artistas - porém é o pensamento de corpo/dança que irá mediar a criação de metodologias que permitam organizar, coerentemente, repertórios diferentes em forma de obra de dança. O pensamento de corpo pode manter a coerência do processo, dificultando que caia em armadilhas mercadológicas, por exemplo: criar uma sequencia coreográfica bonita e funcional não significa que se está discutindo determinado assunto no corpo.

As fronteiras movediças das artes do corpo convidam a uma constante busca por um trabalho técnico que dê conta de problematizar a diversidade de referências sem separar pensar e fazer. A técnica Klauss Vianna propõe princípios que fomentam a busca estética, à medida que a técnica acontece no corpo. É a manutenção do estado de presença que fomenta constantemente a investigação.

Certamente existe forte relação entre construção dramatúrgica e o diálogo entre método e técnica, pois as duas coisas caminham inseparáveis: pensar-fazer. A metodologia diz respeito ao como fazer algo, porém este como pode manter ou não a coerência do pensamento de corpo que apoia uma técnica.

Método e técnica dizem respeito à capacidade de fazer bem as coisas, todas as coisas, inclusive dançar. A questão é que, quando esse tipo de capacitação se transforma em tema, geralmente passa a ser trabalhado dentro de uma separação entre fazer e pensar que lhe traz consequências importantes de serem identificadas. (KATZ, 2009, p. 26)

Os princípios que regem a técnica Klauss Vianna podem manter o estado investigativo sem propor modelos de movimento a copiar, através da escuta do próprio corpo, sempre reafirmando seu não acabamento e suas 
múltiplas possibilidades de relação com o mundo. "A hipótese é a de que a habitual separação entre método e técnica não pode ser sustentada quando se conhece como o corpo funciona" (KATZ, 2009, p. 26).

[...] o que diferencia as técnicas é o entendimento que se tem do corpo e como este acarreta uma determinada metodologia, com seus conceitos e princípios, assim como o conjunto de elementos trabalhados e as instruções para implementá-los nos corpos, em função dos objetivos da visão de corpo que sustenta a técnica. (NEVES, 2010, p. 69)

Em um processo criativo autoral, as metodologias de criação também fazem parte da criação da obra, e as escolhas dos recortes são mediadas por parâmetros também propostos pelo artista. A metodologia também é inventada; o artista segue suas próprias instruções para investigar e escolhe a partir de seus próprios parâmetros. O caminho não está desenhado a priori, a criação é um processo de descobertas e de invenção.

Desde 2007, sou responsável pela dramaturgia e direção dos trabalhos da Cia Corpocena ${ }^{2}$. Desempenhar essas funções conjuntamente talvez tenha contribuído para esclarecer a necessidade de sistematizar algumas metodologias de criação e também para observar que alguns procedimentos contradizem princípios da técnica escolhida - no caso, a técnica Klauss Vianna. Tenho observado que a elaboração de um enunciado provocador de uma resposta cênica que não seja previsível é problema recorrente nos processos de criação. A elaboração de um enunciado, seja ele em forma de pergunta ou não, reflete em sua resposta e, não poucas vezes, induz a uma resposta. A pergunta deveria ser um provocador da investigação, propondo reflexão e escolhas, mas isso nem sempre acontece, sendo possível diferenciar questões que se desdobram em outras, fomentando a investigação das que são simplesmente respondidas sem muita complexidade - é, portanto, uma espécie de falsa questão.

Tenho observado que a escolha de uma técnica gera uma série de outras escolhas que dizem respeito ao pensamento de corpo e ao modo como, de alguma maneira, os princípios da técnica passam a reger o processo de criação

2. A Cia. Corpocena desenvolve pesquisa em dança contemporânea, explorando as possibilidades de diálogo com outras artes da cena: performance e teatro. 


\section{Valquiria Moura Vieira}

como um todo. Em um primeiro momento, falar em mediação de um processo de criação a partir de uma visão de corpo/mundo pode parecer óbvio, mas, na prática, não é tão simples assim; é necessário ter muita atenção para manter a coesão. É preciso não desistir de fazer perguntas e testar muitas possibilidades de resposta para não interromper o processo de investigação.

Por não separar o trabalho técnico do trabalho criativo, a técnica Klauss Vianna, na articulação de seus princípios, tópicos de movimento e instruções para investigação vai, aos poucos, evidenciando incoerências que em outro momento passaram despercebidas. A elaboração ou reelaboração de um enunciado pode evidenciar a confusão de conceitos e contradições em relação à proposta estética, e, quando menos esperamos, somos surpreendidos por um novo olhar para o que já estava estabelecido.

É preciso reconhecer para poder diferenciar. No corpo é assim: somente posso transformar um padrão de movimento quando o reconheço. É a presença que possibilita a leitura da ação em curso, mas é a clareza de princípios que irá mediar às escolhas.

À medida que a opção por uma técnica/pensamento se firmou como escolha da Cia. Corpocena, mudaram os critérios de seleção de materiais e a criação e combinação de procedimentos tornaram-se mais coesas. A construção dramatúrgica está atrelada à escolha da técnica e, portanto, ao pensamento de corpo, pois é esse pensamento que irá mediar o processo.

Sucede que, no corpo, a repetição vai conduzindo um processo de seleção natural da melhor maneira que o corpo encontra para lidar com o movimento. No corpo, tudo aparece com uma forma, e todas as formas se aprontam de acordo com os princípios gerais que regulam as relações corpo-movimento, estejam ou não apresentados na forma de passos codificados de dança. O movimento que não começa copiando um passo existente também tende a ganhar estabilidade, ao longo do tempo, nesse processo de seleção via repetição. Certo modo específico de se mexer acaba por particularizar-se por meio das ações praticadas pelo corpo. Princípios gerais são mais estáveis, mas também estão no eixo do tempo, e em ritmo mais lento, vão transformando-se, à medida que o corpo vai repetindo suas práticas, seus experimentos. A questão desloca-se: não diz mais respeito à existência ou não do passo de dança, mas sim a quando esse "passo" vai passar a existir, se antes ou depois da repetição. (KATZ, 2009, p. 29) 
Ao trabalhar com a técnica Klauss Vianna, cada corpo organiza um repertório de movimentos que pode ser novamente desestabilizado por novas instruções, criadas a partir dos mesmos princípios, até novamente ganhar estabilidade. A necessidade de criar novas instruções e/ou formas de trabalhar um tópico de movimento ${ }^{3}$ fomenta o processo investigativo e, consequentemente, o estado de presença que possibilita as escolhas dramatúrgicas.

\section{O procedimento dramatúrgico como metodologia}

Ainda hoje é comum referirmo-nos à criação artística como fruto da inspiração ou da genialidade de poucos. Para mudar isso, precisamos afirmar que há metodologias de trabalho na criação artística. $\mathrm{O}$ artista precisa criar metodologias para que as ideias se materializem em cena. Não como uma série de passos a seguir para alcançar um resultado definido a priori, mas como criação de estratégias que mobilizem o processo de investigação. A forma de trabalhar também é inventada; o artista vai seguindo suas próprias instruções e escolhendo a partir de seus próprios parâmetros. O procedimento já é criação e, portanto, parte da obra.

O desafio é o de realizar uma reversão do sentido tradicional de método - não mais um caminhar para alcançar metas prefixadas (metá-hódos), mas o primado do caminhar que traça, no percurso, suas metas. A reversão, então, afirma um hódos-metá. A diretriz cartográfica se faz por pistas que orientam o percurso da pesquisa sempre considerando os efeitos do processo do pesquisar sobre o objeto da pesquisa, o pesquisador e seus resultados. (PASSOS; BARROS, 2015, p. 17)

Ao nos voltarmos para o processo de construção dramatúrgica, tal ponto de vista pode enriquecer a elaboração de estratégias de criação e evidenciar seu caráter experimental (proponho nomeá-las de "procedimentos dramatúrgicos"). Esses procedimentos são fundamentais para a construção de uma obra cênica à medida que são os desestabilizadores que movimentam o processo; mobilizados por eles, geramos materiais cênicos que são sele-

3. A técnica Klaus Vianna foi sistematizada em três estágios: processo lúdico, composto por sete tópicos corporais (presença, articulações, peso, apoios, resistência, oposições e eixo global); processo dos vetores e processo criativo e/ou didático. 


\section{Valquiria Moura Vieira}

cionados e problematizados, transformando-se em cena, em um processo quase artesanal.

Somente atividades que problematizem o já conhecido, não só no nível da materialidade do corpo, mas também no nível das relações espaço-temporais que o movimento propõe, terá a potência de atualizar os meios de investigação destinados à proposição de outras linguagens. (HERCÓLES, 2011, p. 21)

A permanência de um material cênico o estabelece como parte da obra, sem que isso tenha sido definido a priori. O objetivo da criação não é alcançar um modelo, mas na investigação que possibilita escolhas; a instabilidade move o processo até que algo se estabilize no corpo por fazer muito sentido e, novamente, ser desestabilizado por uma nova pergunta e/ou uma nova conexão que o transforme, sendo, portanto, uma dramaturgia em movimento.

Em todo processo de mudança, de evolução, existe um momento crítico e instável, como no caminhar: no momento em que estamos dando um passo à frente e nos encontramos com um pé no chão e outro no ar corremos o risco do desequilíbrio e da queda. É a crise - mas é também somente através desse risco que podemos alcançar nosso objetivo. (VIANNA, 2005, p. 67)

O que mobiliza o processo de criação é a própria busca, as perguntas que aparecem diante de pistas e as escolhas que se intercambiam - em um processo dinâmico. Por não apartar técnica e criação, priorizando a investigação do movimento, a técnica Klauss Vianna abre espaço para a complexidade. No entanto, como potencializar possíveis questões que emergem em meio às instruções sem "engessar" os materiais cênicos criados antes mesmo de desdobrá-los?

Escolher um trabalho técnico que tem a investigação como princípio não é suficiente para abranger a complexidade da cena; não impede o surgimento de procedimentos dramatúrgicos que carreguem uma lógica que, de alguma forma, pré-determina o resultado, barrando a continuidade de um processo investigativo. Definir o material que será desenvolvido é diferente de definir sua forma final, portanto eu escolho como investigar para que a forma se desenhe, ou seja, crio e experimento um procedimento, e é essa ação que irá 
reverberar em dramaturgia. Ao escolher um material para desenvolver, essa escolha é envolvida por muitas perguntas: Quais são as leituras possíveis? O que falta? O que pode ser potencializado? A partir disso, é possível identificar por onde seguir com a investigação. Por exemplo: se eu identifico que um material coreográfico está em uma dinâmica linear e isso o distancia, ou não dá conta, do tema escolhido para desenvolver, pela lógica aqui proposta, a escolha seria criar uma instrução/procedimento para investigar dinâmicas possíveis, o que seria diferente de, aleatoriamente, optar por "acelerar aqui" e/ou "ralentar ali".

Ao expandir minha percepção, abro espaço para infinitas possibilidades de conexões que podem - e, no caso da criação artística, é necessário e desejável - ser exploradas, para que gerem outras conexões. Um procedimento de criação também pode fechar possibilidades, propondo um resultado a priori, o que divergiria do pensamento da técnica Klauss Vianna. É necessário continuar fomentando o estado investigativo problematizando os materiais criados com perguntas que mantenham o corpo em ação. "A dramaturgia do corpo não é um pacote que nasce pronto, um texto narrado por um léxico de palavras, mas como a sua etimologia propõe, emerge da ação" (GREINER, 2005, p. 81).

Os procedimentos dramatúrgicos articulam as complexas redes de relações formadas ao longo de um processo criativo entre todos os textos que podem compor a cena - o corpo em relação, corpomenteambiente. Também fazem parte dessa rede os critérios de seleção e de organização de materiais que mediam as escolhas que se dão durante todo o processo, até que o artista escolha o momento de "parar", mesmo que esta parada seja também temporária. "Não se trata de uma desvalorização da obra entregue ao público, mas da dessacralização dessa como final e única forma possível" (SALLES, 2006, p. 14). Experimentar um procedimento de criação já é dramaturgia; portanto, é uma escolha do artista levar o procedimento à cena como proposta dramatúrgica, ou dar a ele uma nova organização.

A estrutura dramatúrgica, mesmo que seja móvel ou flexível, se dá a partir do reconhecimento do que está em curso - para que seja possível fazer escolhas - e é a presença que possibilita isso. Não existe uma lista prévia do que deve ser reconhecido; o reconhecimento se dá por nexo de sentidos e cria os parâmetros que vão compondo a estrutura. 


\section{Valquiria Moura Vieira}

Nesse sentido, dramaturgia é proposta como uma complexa rede de sentidos; tudo o que está ao alcance da percepção faz parte dessa rede. Cada vez que associo uma nova informação com outras que já fazem parte de meu repertório, ela passa a fazer parte da rede. "O corpo não é um meio por onde a informação simplesmente passa, pois toda informação que chega entra em negociação com as que já estão" (GREINER, 2005, p. 131). Nesse caso, o repertório do publico também altera a dramaturgia proposta pelo artista, pois, a partir do momento em que se opta por uma organização não linear e literal, não há como controlar as leituras possíveis.

Não se trata de uma série estática de representações, e, nesse sentido, a comunicação não pode ser restrita a significados. Afinal nem tudo o que se comunica opera em torno de mensagens já codificadas. Há taxas diferentes de coerência, incluindo, por exemplo, a comunicação de estados e nexos de sentido que modificam o corpo. (GREINER, 2005, p. 133).

A possibilidade de olhar para o corpo e para a dramaturgia como algo processual foi - e continua sendo - construída no tempo.

A partir destes coreógrafos, estão criadas as condições para que o corpo deixe de ser pensado como ornamento, no caso de Noverre, ou como legenda, no caso de Fokine, de algo que ocorre além da sua materialidade. As ideias surgidas naqueles períodos pavimentam o caminho para que, hoje, a noção de espetáculo como produto final seja substituída pela ideia de um produto cênico que represente uma solução possível, em constante processo de transformação; que o corpo seja entendido como um meio ativo e processual e não simplesmente como uma espécie de fábrica que apronta produtos; que o movimento seja visto como algo que é reconstruído a cada processo e não como a execução de um modelo dado a priori. (HERCÓLES, 2005, p. 20)

A construção dramatúrgica é um exercício contínuo de percepção, bem como de fazer perguntas e testar possibilidades de respostas. É a partir do perceber e perguntar que as escolhas se dão, fomentando a continuidade e a organização. As perguntas fazem parte do diálogo com os materiais cênicos criados, mediadas pela técnica escolhida pelo artista, pelo tema em questão e pelas referências que pautam cada processo. O que não quer dizer que a coerência esteja ligada a uma lógica linear e homogênea de ideias; há espaço 
para contradições e ruídos de diversas naturezas, uma vez que isso esteja proposto nos parâmetros criados pelo artista.

\begin{abstract}
À medida que tecnicamente vou mudando meus espaços, meu eixo, minha flexibilidade e equilíbrio, trabalho também minha visão de mundo, minha ótica das coisas e das pessoas. Aprender a questionar objetivamente e a observar a si mesmo são as melhores formas de aprendizado. (VIANNA, 2005, p. 97)
\end{abstract}

A escolha de uma técnica gera uma série de outras escolhas que dizem respeito ao pensamento de corpo - ao modo como os princípios da técnica passam a reger o processo de criação como um todo.

A técnica Klauss Vianna respeita a individualidade de cada artista na busca por um corpo sensível ao diálogo com o mundo. A opção por esta técnica não é suficiente para resolver o problema a priori, pois o processo é vivo e, portanto, precisa ser alimentado como tal, elaborando enunciados que mantenham a possibilidade do imprevisível acontecer. Pensando em fomentar o estado investigativo, é importante não perder de vista os princípios da técnica e, como não poderia deixar de ser, o pensamento de corpo que a sustenta. É preciso não desistir de fazer perguntas e testar muitas possibilidades de resposta para não interromper o processo de investigação.

O pensamento de corpo aqui proposto nos coloca no campo da arte, no lugar do livre pensar; é a liberdade de dar ao meu repertório a combinação que me faz sentido - o corpo como ambiente da invenção: "Dança é aquilo que ela quiser fazer. E o pensamento sobre dança deve com ela se fazer. Que ambos se façam sempre num plano de consciência mútuo - para evitar as idiotias" (LEPECKI, 2000, p. 20). Que a dança se faça da experimentação de possibilidades, da tentativa de responder perguntas e, por que não dizer, da invenção de possibilidades de mundo.

\title{
Referências bibliográficas
}

BRASIL, A. C. C. A. Dança e imaginação. 2014. 246 f. Tese (Doutorado em Artes da

Cena) - Instituto de Artes, Universidade Estadual de Campinas, Campinas, 2014. GREINER, C. O corpo: pistas para estudos indisciplinares. São Paulo: Annablume, 2005. HERCÓLES, R. M. Formas de comunicação do corpo - novas cartas sobre a dan- 


\section{Valquiria Moura Vieira}

ça. 2005. Tese (Doutorado em Comunicação e Semiótica) - Pontifícia Universidade Católica de São Paulo, São Paulo, 2005.

A não representação do movimento. In: RENGEL, L.; THRALL, K. (orgs.).

Coleção corpo em cena. v. 2. São Paulo: Anadarco, 2011. p. 11-32.

KATZ, H. Por uma damaturgia que não seja uma liturgia de dança. Sala Preta, São

Paulo, v. 10, p. 163-167, 2010.

Método e técnica: faces complementares do aprendizado em dança. In:

SALDANHA, S. (org.). Angel Vianna, sistema, método ou técnica? Rio de Janeiro: Funarte, 2009. p. 26-32.

LEPECKI, A. Planos de composição. In: GREINER, C.; ESPÍRITO SANTO, C.; SO-

BRAL, S. (orgs.). Cartografia: Rumos Itaú Cultural Dança 2009-2010. São Paulo: Itaú Cultural, 2010.

MILLER, J. A escuta do corpo - sistematização da técnica Klauss Vianna. 2. ed.

São Paulo: Summus, 2007.

Qual é o corpo que dança?: Dança e educação somática para adultos e crianças. São Paulo: Summus, 2012.

NEVES, N. A técnica como dispositivo de controle do Corpomídia. 2010. Tese (Doutorado) - Pontifícia Universidade Católica de São Paulo, São Paulo, 2010.

PASSOS, E.; BARROS, R. B. A cartografia como método de pesquisa-intervenção. In: PASSOS, E.; KASTRUP, V.; ESCÓSSIA, L. (orgs.). Pistas do método da cartografia: pesquisa-intervenção e produção de subjetividade. Porto Alegre: Sulina, 2015.

SALLES, Cecília Almeida. Redes de criação: construção da obra de arte. Vinhedo: Horizonte, 2006.

VIANNA, K. A dança. 6. ed. São Paulo: Summus, 2005.

VIEIRA, J. A. Ciência: formas de conhecimento, uma visão a partir da complexidade.

Fortaleza: Expressão, 2007.

Recebido em 04/07/2015

Aprovado em 13/10/2015

Publicado em 21/12/2015 